\title{
What Is Going Through Your Mind? Thinking Aloud as a Method in Cross-Cultural Psychology
}

\section{Dominik Güss*}

Department of Psychology, University of North Florida, Jacksonville, FL, United States

Thinking aloud is the concurrent verbalization of thoughts while performing a task. The study of thinking-aloud protocols has a long tradition in cognitive psychology, the field of education, and the industrial-organizational context. It has been used rarely in cultural and cross-cultural psychology. This paper will describe thinking aloud as a useful method in cultural and cross-cultural psychology referring to a few studies in general and one study in particular to show the wide applications of this method. Thinking-aloud protocols can be applied for (a) improving the validity of cross-cultural surveys, (b) process analysis of thoughts and the analysis of changes over time, (c) theory development across cultures, (d) the study of cultural meaning systems, and (e) individual as well as group level analyses allowing hypothesis testing cross-culturally.

OPEN ACCESS

Edited by:

Yukiko Uchida,

Kyoto University, Japan

Reviewed by:

Masataka Nakayama

Carnegie Mellon University,

United States

Kimin Eom

University of California,

Santa Barbara, United States

*Correspondence:

C. Dominik Güss

dguess@unf.edu

Specialty section:

This article was submitted to

Cultural Psychology,

a section of the journal

Frontiers in Psychology

Received: 24 January 2018

Accepted: 05 July 2018

Published: 13 August 2018

Citation:

Güss CD (2018) What Is Going Through Your Mind? Thinking Aloud

as a Method in Cross-Cultural

Psychology. Front. Psychol. 9:1292.

doi: 10.3389/fpsyg.2018.01292
Limitations of the thinking-aloud method are also discussed.

Keywords: thinking aloud, verbal protocols, transitional probability, cross-cultural, culture, complex problem solving

\section{INTRODUCTION}

Thinking aloud is the concurrent verbalization of thoughts while performing a task (Ericsson and Simon, 1993). When this method is applied, participants are asked to spontaneously report everything that goes through their minds while doing a task, and they are instructed not to interpret or analyze their thinking. Verbal protocol is another term often used as a synonym for thinking aloud. Verbal protocols can be concurrent (thinking aloud) or retrospective, referring to short reports after the completion of a task.

The study of thinking aloud and of verbal protocols has a long tradition in psychology. It can be traced back to Wilhelm Wundt's technique "Selbstbeobachtung" (self-observation, also often called introspection; Wundt, 1888). Wundt asked participants in his experiments to look inward, pay attention to their inner thought processes, and describe them in detail. Wundt perceived the inner experience, the flow of consciousness, as the core topic of psychology. He saw selfobservation as an appropriate method for studying this flow of consciousness when it occurred under controlled conditions in the laboratory. Some researchers criticized the method, believing that self-observation would interfere with the thought process and, thus, would not show the real thought process itself, but rather an interpretation of the thought process (Ericsson and Crutcher, 1991).

The thinking-aloud method was heavily criticized by behaviorists, as they assumed cognitive processes, such as memory, could not be studied scientifically. As Watson (1925) expressed, "The behaviorist never uses the term memory. He believes that it has no place in an objective psychology" (p. 177). The thinking-aloud method became popular again after the influence of behaviorism 
diminished in mainstream psychology and cognitive psychology became the dominant paradigm. Newell and Simon (1972), for example, asked participants to think aloud while solving particular problems. Rather than investigating whether a person solved a problem or not, their focus was on the process of human reasoning while solving problems. From these thinking-aloud protocols, they derived the computer-simulated model "General Problem Solver."

A study conducted by Ericsson and Chase (1982) on exceptional memory showed that a student could increase his digit span from 7 (e.g., 3-5-1-3-7-8-2), the average number of digits a person is able to remember, to 80 digits by training $1 \mathrm{~h}$ per day, three to five times a week for 20 months. Retrospective verbal protocols showed that the participant used specific mnemonics to help him remember. One mnemonic was to group the digits together in meaningful units, which is called chunking. For example, the three digits 351 could be grouped together as one chunk of " 3 min $51 \mathrm{~s}$ - close to world record mile time," which, if the participant was a long-distance runner, as this participant was, would make sense and, thus, would be easier to remember. Since the publication of Ericsson and Chase's work, thinking aloud has been recognized as an acceptable and even essential method in the study of human cognition.

\section{THE WIDE APPLICATION OF THE THINKING-ALOUD METHOD}

Thinking aloud as a scientific method has been used in many other disciplines, showing the relevance and applicability of this method. Not only researchers studying cognition (e.g., Fleck and Weisberg, 2004; Hölscher et al., 2006; Malek et al., 2017), but also researchers studying education (e.g., Cummings et al., 1989; van den Bergh and Rijlaarsdam, 2001; Bannert, 2003; Kesler et al., 2016), text comprehension using computer based tools (Muñoz et al., 2006; Van Hooijdonk et al., 2006; Wang, 2016), discourse processing (Long and Bourg, 1996), software engineering (Hughes and Parkes, 2003), psychology and law (Santtila et al., 2004), sport psychology (e.g., Samson et al., 2017), and business management (Isenberg, 1986; Premkumar, 1989; Hoc, 1991) have applied the thinking-aloud method. In a similar form, thinking aloud has also influenced the fields of counseling and clinical psychology, for example, in the assessment of automatic thoughts as part of cognitive therapy in depression (e.g., Meichenbaum, 1980; DeRubeis et al., 1990).

\section{RELIABILITY AND VALIDITY OF THINKING-ALOUD PROTOCOLS}

Following positivism, reliability and validity are central to research. Reliability of thinking-aloud data refers to consistency, the ability to collect the same data at a different time. In order to get reliable data, a clearly understandable, tape or digitally recorded thinking-aloud protocol is necessary, which requires control of the experimental situation. Problems related to transcribing and especially to coding have to be minimized, and, ideally, transcription should be done by native speakers of the participants' language. The first step of coding is the segmentation of the whole protocol, i.e., the creation of separate meaningful units, depending on the research questions of interest. Usually those statements are in the form of clauses or sentences; these sentences do not need to be complete, necessarily, as participants use colloquial language. The second step refers to the coding of the segments. A detailed coding system and thorough training of coders can increase reliability, resulting in higher inter-coder reliability. This reliability is sometimes described in percent of agreement, but preferably should be described in Cohen's Kappa or intraclass correlation coefficients. According to Fleiss (1981), a Kappa value over 0.75 is excellent, between 0.60 and 0.75 is good, and a Kappa between 0.40 and 0.60 is fair. One problem that may be encountered during coding is coder biases or expectations, as can occur when the coders are aware of the hypotheses to be tested, for example. Ideally, then, the coders should not know about the research hypotheses. Also, probable biases or expectations can be acknowledged early to increase trustworthiness of the coding process and, consequently, of the data.

Also at issue is the internal validity of a study. In the context of thinking aloud, the validity question is often framed as the reactivity question. Does the act of thinking aloud interfere with and change a person' cognitive processes while performing the task? Ericsson and Simon (1993) argued that it did not, citing many studies and stating that as long as the instruction was clear, i.e., that participants should say out loud everything that went through their minds, thinking aloud did not alter the sequence of thoughts. However, prior consideration should be given to the way instructions are to be conveyed to participants. An instruction from a facilitator to "keep talking" while the participant performed a task probably would not disrupt the thought process, though an instruction requiring explanation from the participant, like "Tell me why you did this," would intervene in the cognitive process by triggering a specific answer to explain an action. If verbal protocols are asked from participants after completion of tasks, it is preferable if verbalization almost immediately follows the task. Generally, a concurrent thinking-aloud protocol has higher validity than a retrospective report, particularly when the task takes a long time to complete.

One way to ensure reliability and validity and to determine whether thinking aloud influences a cognitive process is to create two groups: an experimental group that receives instruction to think aloud, and a control group that does not receive such instruction.

\section{QUALITATIVE EVALUATION CRITERIA: TRUSTWORTHINESS OF THINKING-ALOUD PROTOCOLS}

Researchers conducting qualitative studies use different criteria to evaluate the quality of their research. Whereas quantitative 
psychologists try to discover general universal laws, qualitative researchers try to understand participants' "lived experience" (Hesse-Biber and Leavy, 2006, p. 62), assuming a socially constructed reality. Lincoln and Guba (1999) described four criteria guaranteeing the trustworthiness of the research: credibility, transferability, dependability, and confirmability. Credibility refers to how confident one can be regarding the truth of a study's findings. One way to support credibility is to be open to the possibility of falsification and to conduct a "negative case analysis" (Hesse-Biber and Leavy, 2006 , p. 63), i.e., to include cases that contradict or are not in line with the conclusions drawn so far. It speaks for the researcher if he or she is willing to include those cases in the analysis and, as a result, is able to revise the previously drawn conclusions. A second method to support credibility is triangulation. Triangulation can refer to the use of several methods or several sources of information to investigate the same research question. Thinking aloud, for example, could be combined with post-experiment interview or survey data. Triangulation can also refer to different investigators working on the same data set. This is especially relevant for cross-cultural studies and analyses of thinkingaloud protocols. The underlying assumption of triangulation is that it provides a fuller and more credible picture of the phenomenon. Extended experience in the environment can also increase credibility, and it is especially important for crosscultural psychologists to learn about the other culture and learn the language in order to get a deeper understanding of the utterances made by the participants in the thinking-aloud protocols.

Transferability refers to the application of the findings to other contexts or other people. Quantitative researchers pursue random sampling. Qualitative studies often include small sample sizes and pursue purposive sampling with the goal of getting a wide variety and range of information that can increase the transferability.

Dependability is the third criterion and refers to a study's reliability. Confirmability, the fourth criterion, refers to the accuracy of findings, and to what extent they were influenced by the researcher's biases. Researchers can increase both dependability and confirmability by journaling their experiences and biases and by engaging in dialog with other researchers early on in the research process. Participatory research and peer review (Willis, 2007) can also increase dependability and confirmability. In participatory research, the researcher presents initial conclusions of the study to the participants and actively involves them in the research process. For example, thinkingaloud protocols could be shown to and discussed with the participants and ambiguities in the protocol could be clarified. Peer review is similar to triangulation involving other researchers. In cross-cultural research, the ideal, as mentioned before, would be collaboration with a researcher from the target culture. It is recommended to involve other researchers early in the research process and to stay in continuous dialog with them about the research progress.

\section{CROSS-CULTURAL PSYCHOLOGICAL RESEARCH USING THINKING-ALOUD AND VERBAL PROTOCOLS}

One goal of cross-cultural psychology is "the study of similarities and differences in individual psychological functioning in various cultural and ethnocultural groups" (Berry et al., 2002, p. 3). The thinking-aloud method, however, is rarely used in crosscultural research. A search in PsychInfo, January 2018, with no time limitation showed 503 hits for the term "thinking aloud" used anywhere and 464 hits for the term "verbal protocols" used anywhere. Only six peer-reviewed journal articles were found for the combination of the word "thinking aloud" or "verbal protocol" anywhere with either one of the two keywords "culture" or "cross-cultural."

Luria (1976) studied reasoning, among other cognitive processes, in Central Asia, comparing illiterate peasants (the term used by Luria), barely literate kolkhoz farm workers, and young people with a few years of schooling. He used an interview technique to investigate the thought processes of the participants. He presented participants with syllogisms such as the following: "Cotton grows well where it is hot and dry. England is cold and damp. Can cotton grow there or not?" (p. 107).

Results showed that illiterate participants who had no formal education had difficulties solving the syllogisms. Luria was not only interested in the outcome, how many of the participants of each group could solve the syllogism correctly, but even more so in their reasoning, how they interpreted the syllogism. The illiterate participants interpreted the syllogisms on the basis of their experiences in a concrete way and did not show abstract thinking. Only the analysis of participants' thought processes allowed Luria to answer the question of why illiterate participants had difficulties interpreting the syllogisms.

The following is part of a short conversation the interviewer had with a 37-year-old illiterate villager who was presented with the cotton syllogism. It is, however, more an interview than a mere thinking-aloud protocol.

Interviewer: "Cotton can grow only where it is hot and dry. In England, it is cold and damp. Can cotton grow there?"

Participant: "I don't know."

Interviewer: "Think about it."

Participant: "I've only been in the Kashgar country. I don't know beyond that."

Interviewer: "But on the basis of what I said to you, can cotton grow there?"

Participant: "If the land is good, cotton will grow there, but if it is damp and poor, it won't grow. If it's like the Kashgar country, it will grow there too. If the soil is loose, it can grow there too, of course" (Luria, 1976, p. 108).

Luria also used grouping tasks where participants were presented with several objects and had to find, which ones belong together and which ones did not. This task assesses categorical classification. The following is the response of a 60 -year-old illiterate peasant who was shown pictures of a hammer, a saw, a log, and a hatchet. 
They all fit together! The saw has to saw the log, the hammer has to hammer it, and the hatchet has to chop it. And if you want to chop the log up really good, you need the hammer. You can't take any of these things away. There isn't any you don't need (Luria, 1976, p. 58).

This thinking-aloud statement related to the classification task shows the participant's situational thinking. The participant does not classify the objects into a more abstract category, but refers to their "practical utility" (p. 59). Similar studies on formal and informal education and its influence on problem solving, reasoning, or intelligence were reported by Scribner (1979) and Scribner and Cole (1981), who also instructed participants to verbalize their thoughts when solving certain cognitive tasks. These studies show that thinking aloud can tap into information that cannot be analyzed by other methods alone, explaining the differences or accessing the nuances usually not revealed through other forms of data gathering.

\section{Cultural Meanings 1: Improving the Validity of Cross-Cultural Surveys Using Thinking Aloud}

Raitasalo et al. (2005) used the thinking-aloud method in a crosscultural study in Finland, Germany, Italy, and the Netherlands to investigate cultural differences in answering survey items. The survey focused on alcohol use: frequency of drinking, quantity of drinking, frequency of drunkenness, and the context of drinking in the last 12 months. For our purposes, the major finding of interest is cross-cultural differences related to the understanding of the survey questions. We can conclude from this study that allowing participants in cross-cultural studies to verbalize or write down their thoughts when answering Likert-scale survey questions could show the researcher(s) how the participants understand the questions and which cultural meanings participants attribute to these questions. Thinking aloud can also point out the interpretations participants give to the survey questions.

To illustrate this point, I would like to quote two survey questions used in studies published in the Journal of CrossCultural Psychology. The first one refers to Keller et al. (2006), who used the Family Allocentrism Scale (Lay et al., 1998) as one of their measurements. Lay et al. tested for response bias and conducted item analyses with western and eastern samples when they developed their survey. One item of this scale is "My family's opinion is important to me." Thinking aloud of participants from different cultural groups regarding this question could be especially beneficial in the first stages of scale development and could reveal (a) if participants think of specific family opinions, (b) if so, which ones they are referring to when answering this question, and (c) who and what defines family: a nuclear family; an extended family with grandparents, uncles, aunts; only one caregiver; or if family is interpreted as only the participant, the individual. One western participant could express, for example: "No, their opinion is not important to me when they want to tell me which clothes I should wear." Another participant could say, "Sure, I listen to their advice regarding my future major at the university. After all, they will support me." Another participant might say, "I listen to my mom, because she understands me, but not to my dad, and certainly not to my brothers." These different answers show that participants understand the question in different ways and participants' answer choices depend on what they are thinking of at the time. One could specify the question, for example: "My mother's opinion regarding my professional future is important to me."

A second example is an item Hershey et al. (2007) used studying retirement planning in the Netherlands and in the United States, a single-item indicator for perceived savings adequacy: "I am saving enough for retiring comfortably." A participant in Germany might choose, "1-strongly disagree," thinking aloud, "I do not need to save and I did not save, because I always paid into the social retirement system and I am guaranteed a retirement from the government." An Indian participant might also choose, "1-strongly disagree," thinking aloud, "I do not need to save, because I have four children and they will take care of me; one of them is even a computer programmer in Hyderabad." Additionally, a Filipino might also choose, "1-strongly disagree," but say, "No matter how hard I try, I will never be saving enough for retirement, there is no wellfunctioning system of retirement here. We grow old, we stay with our family, we are loved." Even if the German, Indian, and Filipino have the same survey answer, all indicating that they are not saving for retirement, their thinking-aloud statements show that the underlying reasons for their responses are quite different. The researcher could use those thinking-aloud data to specify the question and perhaps to develop further questions to lessen misinterpretation, garner more accurate responses, or even to be more sensitive to participants' culture. Possible modified items could be "The government is supporting retired people adequately." And "I can rely on my family to support me financially when I retire."

The use of thinking aloud and verbal protocols can be especially helpful when surveys try to assess sensitive topics, meaning topics subject to bias and social desirability, and to those that attempt to be respectful to the context and the larger dimensions of the culture. Edwards et al. (2005), for example, conducted a study on condom use as a preventive measure for HIV/AIDS. They collected thinking-aloud protocols of sex workers problem solving a simulated task. The goal was to improve a sexual behavior survey instrument. The thinkingaloud data helped the authors to improve comprehension of the instrument and to reduce social desirability, providing appropriate terms and cues for aiding recall, improving the establishment of trust with participants, and creating a sense of cultural competence and credibility from the researchers. Vreeman et al. (2014) transcribed and coded cognitive interviews regarding HIV with pediatric caregivers in Kenya in order to further develop and adapt survey items to this cultural context.

Cross-cultural psychologists have a multitude of quantitative methods to increase reliability and validity of survey instruments used in cross-cultural research (for an overview, see van de Vijver and Leung, 1997; van de Vijver and He, 2017). The thinkingaloud method is an additional method that can be used to improve the reliability and validity of self-report instruments (Sudman et al., 1996). 


\section{Cultural Meanings 2: Thinking Aloud Allows for the Study of Cultural Meaning Systems Beyond the Sentence Level}

The previous paragraphs referred to cultural meanings attributed to specific survey items on the sentence and phrase level. Thinking-aloud data can be also analyzed more broadly regarding the meanings expressed by participants going beyond the sentence level. A multitude of other qualitative methods, such as consensual qualitative research methodology (Hill et al., 1997; Güss et al., 2018) or grounded theory (Glaser and Strauss, 1980) can be applied to analyze thinking-aloud protocols for meanings expressed by participants of various cultural and ethnic groups. As Smagorinsky (2001) pointed out, "from a cultural perspective a verbal protocol represents the speaker's cultural conception of the word" (p. 235) and gives insight into his or her cultural world. Needless to say, analysis of such protocols necessarily requires coders from the participants' respective cultures or coders who are multiculturally competent - not only knowledgeable about other cultures, but deeply aware of their own biases and prejudices.

\section{Concrete Examples of Thinking-Aloud Data Analysis From One Cross-Cultural Study}

A study by Güss et al. (2010) illustrates the different options for data analysis using thinking-aloud protocols. The study was conducted in Brazil, Germany, India, Philippines, and the United States with over 500 participants. They were instructed to think aloud while working on two computer-simulated problem -solving tasks. One of the tasks was a computer simulation in which participants took the role of a fire-fighting commander who had to protect three cities and forest from approaching fires. Participants always spoke in their native languages when they thought aloud. However, Indian and Filipino participants often spoke in English. We encouraged participants to use the language they were most comfortable using to minimize potential influences of thinking aloud on the problem-solving process. All the thinking-aloud protocols were tape-recorded, transcribed, and coded. Student volunteers in every country were trained how to transcribe and code the protocols. During the training, the coding system was explained and defined, examples were given, coding was practiced, and the differences between the subcategories were discussed.

Each thinking-aloud protocol was transcribed into Microsoft Excel, so that every statement expressing an idea unit filled one cell. The following example has two different idea units and was therefore transcribed into two cells: "I send truck 5 to city $1 / /$ and then I will clear the forest." Statements were then coded according to the problem-solving stages. The coding system was initially created following the western stage model of problem solving: problem identification, goal definition, information gathering, mental model building, planning of solutions, prediction of further developments, decision-making, action, evaluation of outcome, and modification of strategic approach (e.g., Bransford and Stein, 1993; Dörner, 1996). The system was then modified to account for other statements made by participants. These statements referred to emotions and self-descriptions. The final coding system consisted of 21 categories that were summarized in 8 main categories (Güss et al., 2010).

\section{Testing Theories Across Cultures Using Thinking Aloud}

Table 1 contains verbatim parts of participants' thinking-aloud protocols and includes statements from one U.S. participant (USA15) and one Filipino participant (Phil13). The coding is also indicated (the full coding system is available upon request). These data can be used to test specific hypotheses. Based on a literature review (e.g., Nisbett, 2003), one hypothesis could refer to a more problem-centered and solution/action-oriented focus on problem solving for U.S. participants and a more context-centered focus for Filipino participants. The frequency of categories can be counted and either absolute or relative frequencies can be shown. Figure 1 shows relative frequencies as the time required to complete the thinking-aloud protocols and the number of statements for the U.S. and Philippine participants differed.

The distribution of the problem-solving categories of the complete thinking-aloud protocols shows which categories were used frequently and which ones were not. The most frequent category expressed by the U.S. participant (USA15) was planning, decision-making, and action - roughly one-third of all statements. For the Filipino participant (Phil13), the most frequent category, expressed in more than a quarter of all statements, was negative self-reference (SI). The distribution of the categories differed significantly between the U.S. and Filipino participant, $\chi^{2}(169)=200.27, p=0.05$. The U.S. participant showed relatively more situation description, PI, attributions and predictions, and planning, decision-making, and action. The Filipino participant expressed relatively more information gathering, negative SIs, and laughter. The two participants' data support the hypotheses. Indeed, results indicated a dominance of categories related to problem identification and problem

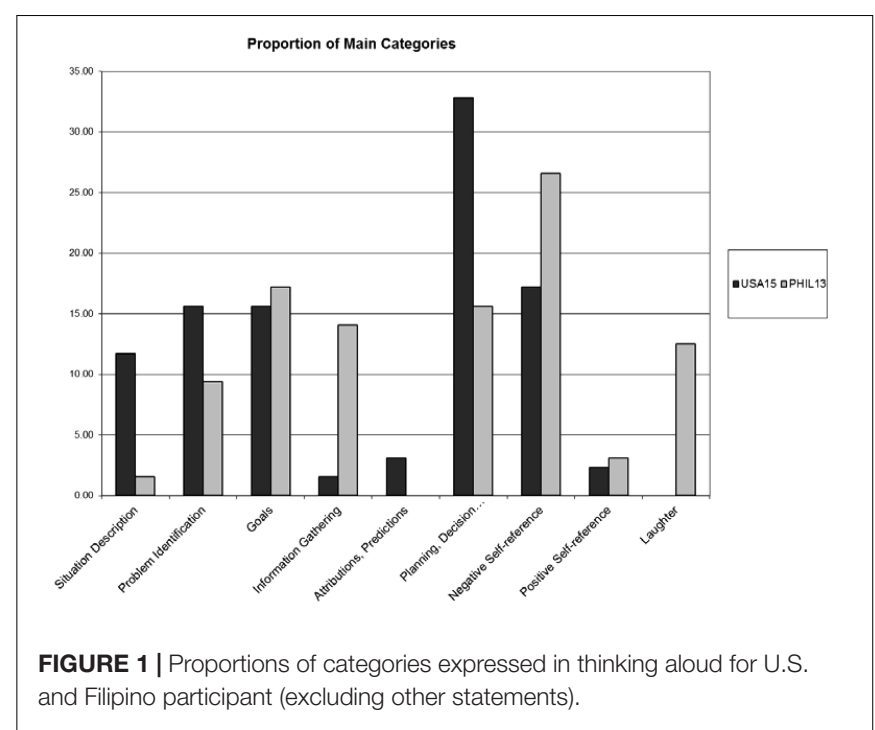


TABLE 1 | Coding and idea unit examples transcribed from a study using the thinking-aloud method.

\begin{tabular}{|c|c|c|}
\hline \multicolumn{3}{|l|}{ USA15 } \\
\hline Send these guys walking around the houses to put some fires out around there & PlanDM & Planning, decision making, and action \\
\hline Huh? & Info & Gathering of information \\
\hline Send the helicopter over to the right & PlanDM & Planning, decision making, and action \\
\hline Because its getting pretty close to the rich people & PlanDM & Planning, decision making, and action \\
\hline Oaauhuh & SR- & Negative self-reference \\
\hline Guess Johnny put out some fires still & AT_Pred & Attributions and predictions \\
\hline Up at the top left or middle left & SD & Situation description \\
\hline Don't want to move that guy because the fire pops up in the middle then & PlanDM & Planning, decision making, and action \\
\hline So still going there & PlanDM & Planning, decision making, and action \\
\hline I need a helicopter and stuff extinguish the fire down there & GO & Formulation of goal \\
\hline Okay, one is moving that way & $\mathrm{SD}$ & Situation description \\
\hline So it's probably not going to hit him & AT_Pred & Attributions and predictions \\
\hline I mean, look at it when its moving & $\mathrm{O}$ & Other \\
\hline Go southeast to the... & PlanDM & Planning, decision making, and action \\
\hline Still trying to put out the fire & $\mathrm{GO}$ & Formulation of goal \\
\hline It's getting closer to the city & $\mathrm{Pl}$ & Problem identification \\
\hline \multicolumn{3}{|l|}{ Phil13 } \\
\hline I forgot already the commands. & SR- & Negative self-reference \\
\hline Click this & GO & Formulation of goal \\
\hline Go to the units & GO & Formulation of goal \\
\hline Click again & GO & Formulation of goal \\
\hline And that's it! & $\mathrm{SD}$ & Situation description \\
\hline Oh no, there again & SR- & Negative self-reference \\
\hline Goal & PlanDM & Planning, decision making, and action \\
\hline Extinguish & PlanDM & Planning, decision making, and action \\
\hline Click again and then extinguish & GO & Formulation of goal \\
\hline I am good. & $\mathrm{SR}+$ & Positive self-reference \\
\hline (Laughs) & $\mathrm{L}$ & Laughter \\
\hline Click again & $\mathrm{GO}$ & Formulation of goal \\
\hline
\end{tabular}

solution for the U.S. participant and a dominance of information gathering to understand the problem context and less solutionfocus for the Filipino participant.

The analysis here refers only to thinking-aloud protocols of two individuals. The same analysis could be conducted for averages of thinking-aloud protocol categories among different cultural groups. Especially when referring to cross-cultural differences and when claiming reliable cross-cultural differences, then the data should be compared at the group level rather than individual level. In fact, a comparison of over 400 Brazilian, German, Filipino, Indian, and U.S. participants' thinking-aloud protocols shows significant cross-cultural differences among exactly these problem-solving categories with medium to large effect sizes (Güss et al., 2010).

\section{Testing Cross-Cultural Generalizability of Psychological Theories Developed in Western Societies Using Thinking Aloud}

The analysis of the thinking-aloud protocols can also be used to test theories that were developed in western industrialized countries for their cross-cultural validity. The dominant theory on problem solving developed in the United States (e.g., Bransford and Stein, 1993) and Europe (e.g., Dörner, 1996) suggests that problem solvers go through certain stages while solving problems. These stages are clarification of goals, gathering information, prediction of further developments, planning, decision-making, action, and evaluation of effects. In the Güss et al.'s (2010) study, many of these stages were indeed found in the thinking-aloud protocols of participants in all five countries. What the western stage model did not consider, however, were statements referring to negative and positive emotions and statements referring to negative and positive self-evaluations (e.g., "I will never be a good fire fighter"). Our data from the five countries showed that problem solving is not solely a cognitive process, but interacts with emotional and selfevaluative processes. The thinking-aloud data from the five countries support the existing stage model. On the other hand, they provide the basis to further develop the model and include emotional and self-evaluative processes.

\section{Testing Predictions and Differences in Performance Using Thinking Aloud}

The thinking-aloud data can also be used as independent variables to test the influence on a dependent variable. One question relevant to the data of the U.S. and Filipino participant refers to which stages can predict performance in the fire simulation. Is it always the same stage or do these stages vary cross-culturally? Analyzing the demands of the simulation, i.e., 
the development of many fires and the requirement to extinguish them fast to avoid their spreading, indicates that the most crucial of the stages is planning, decision-making, and action. Although cross-cultural differences are expected in the frequency of the categories, it is likely that across cultures the same stages predict performance due to the specific task demands. USA15 protected $68.1 \%$ of the forest at the end of the simulations, Phil13 protected $53.1 \%$. Correlations and regression analyses would allow testing those predictions referring to groups of participants. The correlation of performance in the simulation with the frequency of planning, decision-making, and action controlling for the overall number of statements made was $r=0.11, p=0.04(N=349)$. This relationship, however, was not significant for the U.S. sample, $r=0.13$, $n s(n=64)$, and only marginally significant for the Filipino sample, $r=0.22$, $p=0.08(n=62)$.

The effect size (i.e., $r$ ) is smaller in the overall analysis across the United States and Filipino cultures than those within individual cultural samples. However, because of the difference in sample size, the correlation was only significant for the overall analysis. Thus, in this specific case, the result does neither support cultural universality nor cultural differences.

\section{Analysis of Transitions in the Process Using Thinking Aloud}

The thinking-aloud data can be analyzed in more detail. One might ask, for example, if the Filipino participant's laughter is a positive expression related to happiness and other positive emotions or if it is nervous laughter, a coping mechanism relieving negative emotions and tensions. Another question of interest could be related to cultural strategies in problem solving. What do participants do when they identify a problem - for example, a new fire spreading close to one of the cities?

These questions can be answered analyzing the transition probabilities between the stages, also called lag analysis (Bakeman and Gottman, 1986) or latent transition analysis (Lanza et al., 2005). The transitional probability (TP) from any category $x$ to another category $y$ is given by TP $(x \rightarrow y)=$ frequency $(x y)$ /frequency $(x)$.

We could examine the thinking-aloud protocols to discover what statements the Filipino participant made before laughing (L). What is the probability that laughing $(y)$ follows negative self-reference statements $(x)$ ? Or, what statements were made by both participants after they identified a problem (PI)? This analysis can be quite tedious when done manually in long or multiple protocols, so we developed a computer program (Parise and Güss, 2006) that can read the coded files and give an output file with all the possible transitions. The most frequent transitions in the thinking-aloud protocols of USA15 and Phil13 are shown in Figures 2, 3. The figure for PHIL13 shows that laughter was preceded in $24 \%$ of all transitions by negative self-reference statements. This might indicate that laughter was used to cope with negative emotions and negative self-evaluations.

The question above about statements made after PI had to do with culture-specific ways of dealing with problems. The Filipino transitions showed that after PI, the most frequent reaction was

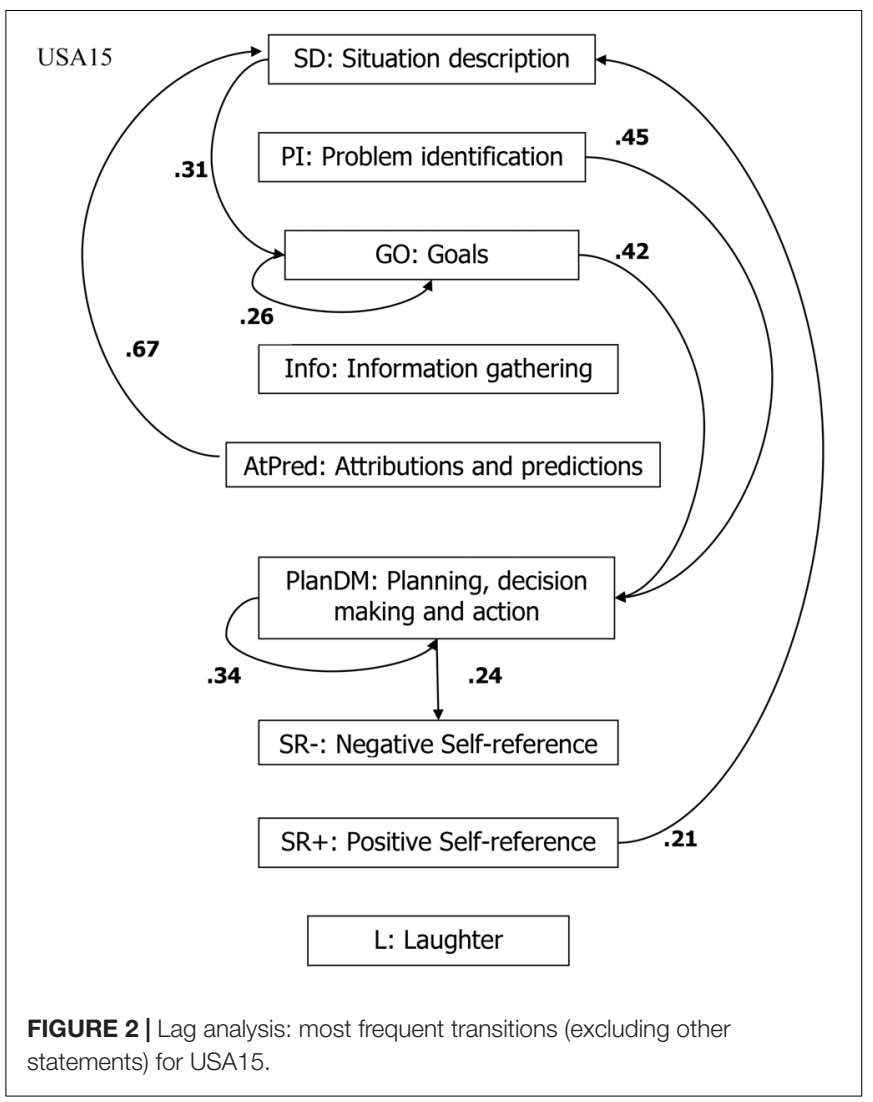

a negative self-reference statement (40\%). The U.S. participant reacted differently. In the figure showing the U.S. participant's transitions, the most frequent transition from PI was to planning, decision-making, and action (45\%). Whereas the Filipino reacted to PIs with negative emotions and self-evaluations, the U.S. participant proceeded right to the solution process.

The previous analyses referred to one Filipino and one U.S. participant. We also created a program (Edwards, 2018) that compiles all the transition frequencies of the 74 Filipino and the 67 U.S. participants. Although laughter happened almost six times more often in the Filipino sample, it was preceded by negative self-references in $24.6 \%$ in the U.S. sample and in $23.2 \%$ in the Filipino sample. The differences we discussed before regarding laughter were not found in the two overall cultural samples.

We also analyzed the thinking-aloud protocol transitions for all Filipino and all U.S. participants regarding the stages following PI. Overall, U.S. participants mentioned problem statements twice as often as Filipino participants. Whereas negative selfreferences followed PI in $14.3 \%$ in the U.S. sample, planning, decision-making, and action followed in $53.4 \%$ of all transitions. In the Filipino sample, negative self-references followed slightly more often, namely in $16.1 \%$ and planning, decision-making, and actions only in $14.4 \%$ of all transitions after PI. The tendency we discussed before to proceed with planning and decision-making after a problem is identified was also found in the U.S. sample overall. 


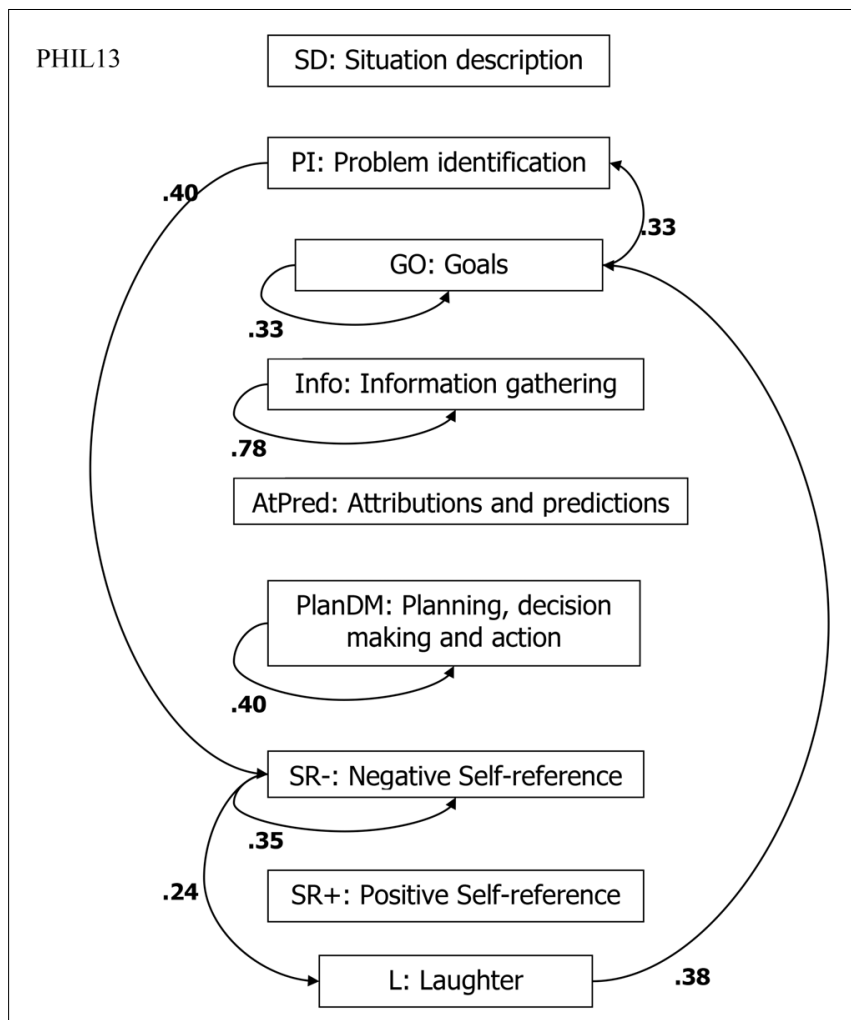

FIGURE 3 | Lag analysis: most frequent transitions (excluding other statements) for Phil13. several fires are burning, decision-making, and action might be the necessary and dominant stage. Toward the end, a participant might reflect on what he or she has accomplished.

Figure 4 shows the first 20 coded statements at the beginning of the fire simulation, 20 coded statements made in the middle of the simulation, and the last 20 coded statements made at the end of the simulation. Due to space limitations, only the process of the U.S. participant (USA15) is shown. As expected in the hypotheses, initially (codes 1-20) the participant verbalized many goal statements and then moved into planning, decision-making, and action followed by some self-reference statements. In the middle of the simulation (codes 61-80), planning, decisionmaking, and action was the dominant stage. Some statements referred to problem identification, situation description, and selfreferences. Toward the end (codes 121-138), however, there is no dominant stage. Every category expressed had a frequency of three or four.

Cross-cultural comparisons could reveal that participants from other cultures follow a different approach. They might, for example, not plan ahead and start with goals, but make decisions right away and act. In fact, a cross-cultural study has shown a more presence orientation and short-term planning in a Brazilian sample compared to a German sample with more pronounced long-term planning (Strohschneider and Güss, 1998).

\section{LIMITATIONS OF THE THINKING-ALOUD METHOD}

As with every method, the thinking aloud method has limitations. One problem might be related to the completeness of the data. First, some participants may not talk consistently and may remain quiet for long periods of time. The experimenter can remind participants briefly and unobtrusively to keep talking, but a few participants will not be able or willing to do so. It may even be that for participants of certain cultures it is unusual, uncomfortable, and unnatural to spontaneously say out loud what they think (see Kim, 2002). The author showed that East Asian Americans had different attitudes regarding talking and thinking aloud compared to European Americans. East Asian Americans regarded talking not as important when solving problems and indicated they talked less often at home with their parents compared to European Americans.

In some cultures, for instance, people learn to keep quiet and stay quiet until they have something worthwhile to say. So there might be some screening or sifting through what they say out loud. In fact, we found cross-cultural differences in the number of statements made during the $12 \mathrm{~min}$ of the simulations, $F(4,386)=23.47, p<0.001$, partial $\eta^{2}=0.196$. For those tapes that were described and contained more than 10 statements, the average number of statements was 88 for Brazilians, 103 for Germans, 82 for U.S. Americans, 69 for Filipinos, and 49 for Indians. Future research will have to address the validity of the thinking-aloud method for various cultural groups. Potentially familiarizing participants with this method and having practice sessions before starting an experiment could be helpful. 


\begin{tabular}{|l|l|l|l|l|l|l|l|l|l|l|l|l|l|l|l|l|l|l|l|l|}
\hline Category & 1 & 2 & 3 & 4 & 5 & 6 & 7 & 8 & 9 & 10 & 11 & 12 & 13 & 14 & 15 & 16 & 17 & 18 & 19 & 20 \\
\hline $\begin{array}{l}\text { Situation } \\
\text { Description }\end{array}$ & & & & & & & & & & & & & & & & & & & \\
\hline $\begin{array}{l}\text { Problem } \\
\text { Identification }\end{array}$ & & & & & & & & & & & & & & & & & & & \\
\hline Goals & & & & & & & & & & & & & & & & & & & \\
\hline $\begin{array}{l}\text { Information } \\
\text { Gathering }\end{array}$ \\
\hline $\begin{array}{l}\text { Attributions and } \\
\text { Predictions }\end{array}$
\end{tabular}

\begin{tabular}{|l|l|l|l|l|l|l|l|l|l|l|l|l|l|l|l|l|l|l|l|l|}
\hline Category & 61 & 62 & 63 & 64 & 65 & 66 & 67 & 68 & 69 & 70 & 71 & 72 & 73 & 74 & 75 & 76 & 77 & 78 & 79 & 80 \\
\hline $\begin{array}{l}\text { Situation } \\
\text { Description }\end{array}$ & & & & & & & & & & & & & & & & & & & & \\
\hline $\begin{array}{l}\text { Problem } \\
\text { Identification }\end{array}$ & & & & & & & & & & & & & & & & & & & & \\
\hline Goals & & & & & & & & & & & & & & & & & & & \\
\hline $\begin{array}{l}\text { Information } \\
\text { Gathering }\end{array}$ & & & & & & & & & & & & & & & & & & & & \\
\hline $\begin{array}{l}\text { Attributions and } \\
\text { Predictions }\end{array}$ & & & & & & & & & & & & & & & & & & & & \\
\hline $\begin{array}{l}\text { Planning, } \\
\text { Decision Making, } \\
\text { and Action }\end{array}$ & & & & & & & & & & & & & & & & & & & & \\
\hline $\begin{array}{l}\text { Positive Self- } \\
\text { reference }\end{array}$ \\
\hline $\begin{array}{l}\text { Negative Self- } \\
\text { reference }\end{array}$
\end{tabular}

\begin{tabular}{|l|l|l|l|l|l|l|l|l|l|l|l|l|l|l|l|l|l|l|}
\hline Category & 121 & 122 & 123 & 124 & 125 & 126 & 127 & 128 & 129 & 130 & 131 & 132 & 133 & 134 & 135 & 136 & 137 & 138 \\
\hline $\begin{array}{l}\text { Situation } \\
\text { Description }\end{array}$ & & & & & & & & & & & & & & & & & \\
\hline $\begin{array}{l}\text { Problem } \\
\text { Identification }\end{array}$ & & & & & & & & & & & & & & & & & & \\
\hline Goals & & & & & & & & & & & & & & & & & & \\
\hline $\begin{array}{l}\text { Information } \\
\text { Gathering }\end{array}$ & & & & & & & & & & & & & & & & & & \\
\hline $\begin{array}{l}\text { Attributions and } \\
\text { Predictions }\end{array}$ & & & & & & & & & & & & & & & & & & \\
\hline $\begin{array}{l}\text { Planning, } \\
\text { Decision Making, } \\
\text { and Action }\end{array}$ & & & & & & & & & & & & & & & & & \\
\hline $\begin{array}{l}\text { Positive Self- } \\
\text { reference }\end{array}$ & & & & & & & & & & & & & & & & & & \\
\hline $\begin{array}{l}\text { Negative Self- } \\
\text { reference }\end{array}$ & & & & & & & & & & & & & & & & & \\
\hline Laughter & & & & & & & & & & & & & & & & & & \\
\hline Other & & & & & & & & & & & & & & & & & & \\
\hline
\end{tabular}

FIGURE 4 | Coded thinking-aloud statements from the beginning, middle, and end of the simulation. 
Second, background noise or a participant with a very soft voice can make it hard to understand the participant's verbal utterances on the tape. To instruct the participant to speak louder might affect the data. It is difficult for a person to change the volume of his or her voice. Speaking louder would most likely require conscious effort, which could possibly limit working memory capacity needed for focusing on the task.

Third, not every cognitive process is active in working memory and can be verbalized. Some psychological processes do not reach consciousness or are automatic processes that cannot be verbalized (Wilson, 1994). Fourth, sometimes a participant may experience various thoughts, but may not have the time to express all of them and, therefore, will be required to select what to report. The fifth limitation is a practical one. The analysis of thinking-aloud protocols is tedious, time consuming, and labor intensive.

An open question refers to the reactivity of thinking-aloud data in various cultures as well as the validity across cultures, as mentioned before. Ericsson and Simon (1993) have put together various studies on verbal reports in Western countries and have shown that it is a quite reliable and valid method if participants are not instructed or stimulated to observe their problem-solving processes and to engage in metacognitive activities that might in turn influence and redirect their problem solving or trigger new thought processes (reactive effects of verbal protocols). Future research will show whether thinking-aloud protocols are also a reliable and valid method of gathering data in non-western countries. Future research could also show for which processes and phenomena across cultures the thinking-aloud method is more and less useful.

\section{CONCLUSION}

Thinking aloud refers to the concurrent verbalization of thoughts while performing a task. It is a method widely used in various areas of psychology, however, not in crosscultural psychology. This paper discussed the limitations of

\section{REFERENCES}

Bakeman, R., and Gottman, J. R. (1986). Observing Interaction. Cambridge: Cambridge University Press.

Bakeman, R., and Quera, V. (1995). Log-linear approaches to lagsequential analysis when consecutive codes may and cannot repeat. Psychol. Bull. 118, 272-284. doi: 10.1037/0033-2909.118. 2.272

Bannert, M. (2003). Effekete metakognitiver lernhilfen auf den wissenserwerb in vernetzten lernumgebungen [Effects of metacognitive help on knowledge acquisition in web-based learning environments]. Z. Pädagog. Psychol. $17,13-25$.

Berry, J. W., Poortinga, Y. H., Segall, M. H., and Dasen, P. R. (2002). Cross-Cultural Psychology. Research and Applications. Cambridge: Cambridge University Press.

Bransford, J. D., and Stein, B. S. (1993). The Ideal Problem Solver: A Guide for Improving Thinking, Learning, and Creativity, 2nd Edn. New York, NY: W. H. Freeman.

Cummings, A. L., Murray, H. G., and Martin, J. (1989). Protocol analysis of the social problem solving of teachers. Am. Educ. Res. J. 26, 25-43. doi: 10.3102/ 00028312026001025 the method and showed its strengths by discussing various opportunities for cross-cultural research: improving validity of cross-cultural surveys by investigating cultural meanings of survey items, investigating psychological processes rather than outcomes across cultures, testing theories cross-culturally, and allowing individual and group-level analyses across cultures. Thus, thinking-aloud protocols can offer additional insights in human minds around the world.

\section{ETHICS STATEMENT}

This study was carried out in accordance with the recommendations of the Institutional Review Board of the University of North Florida with written informed consent from all subjects. All subjects gave written informed consent in accordance with the Declaration of Helsinki. The protocol was approved by the Institutional Review Board of the University of North Florida.

\section{AUTHOR CONTRIBUTIONS}

The author confirms being the sole contributor of this work and approved it for publication.

\section{FUNDING}

This research was supported in part by a research fellowship of the Alexander von Humboldt Foundation and from the University of North Florida's Delaney Presidential Professorship.

\section{ACKNOWLEDGMENTS}

I would like to thank Dr. Ma Teresa Tuason and Shannon McLeish for their thoughtful comments on an earlier version of this article.

DeRubeis, R. J., Evans, M. D., Hollon, S. D., Garvey, M. J., Grove, W. M., and Tuason, V. B. (1990). How does cognitive therapy work? Cognitive change and symptom change in cognitive therapy and pharmacotherapy for depression. J. Consult. Clin. Psychol. 58, 862-869. doi: 10.1037/0022-006X.58.6.862

Dörner, D. (1996). The Logic of Failure. New York, NY: Holt.

Edwards, M. (2018). Thinking-Aloud Transitions Coder. Jacksonville, FL: University of North Florida.

Edwards, M., Thomsen, S. C., and Toroitich-Ruto, C. (2005). Thinking aloud to create better condom use questions. Field Methods 17, 183-199. doi: 10.1177/ 1525822 X04271029

Ericsson, K. A., and Chase, W. G. (1982). Exceptional memory. Am. Sci. 70, 607-615.

Ericsson, K. A., and Crutcher, R. J. (1991). Introspection and verbal protocols on cognitive processes-Two approaches to the study of thinking: a response to Howe. New Ideas Psychol. 9, 57-71. doi: 10.1016/0732-118X(91)90041-J

Ericsson, K. A., and Simon, H. A. (1993). Protocol Analysis: Verbal Reports as Data. Cambridge, MA: MIT Press.

Fleck, J., and Weisberg, R. W. (2004). The use of verbal protocols as data: an analysis of insight in the candle problem. Mem. Cogn. 32, 990-1006. doi: 10.3758/BF03196876 
Fleiss, J. L. (1981). Statistical Methods for Rates and Proportions. New York, NY: Wiley.

Glaser, B. G., and Strauss, A. L. (1980). The Discovery of Grounded Theory. Strategies for Qualitative Research, 11th Edn. New York, NY: Aldine Publishing Company.

Gottman, J. M., and Roy, A. K. (1990). Sequential Analysis: A Guide for Behavioural Researchers. Cambridge: Cambridge University Press. doi: 10.1017/ CBO9780511529696

Güss, C. D., Tuason, M. T., and Gerhard, C. (2010). Cross-national comparisons of complex problem-solving strategies in two microworlds. Cogn. Sci. 34, 489-520. doi: 10.1111/j.1551-6709.2009.01087.x

Güss, C. D., Tuason, M. T., Göltenboth, N., and Mironova, A. (2018). Creativity through the eyes of professional artists in Cuba, Germany, and Russia. J. Cross Cult. Psychol. 49, 261-289. doi: 10.1177/0022022117730817

Hershey, D. A., Henkens, K., and van Dalen, H. P. (2007). Mapping the minds of retirement planners: a cross-cultural perspective. J. Cross Cult. Psychol. 38, 361-382. doi: 10.1177/0022022107300280

Hesse-Biber, S. N., and Leavy, P. (2006). The Practice of Qualitative Research. Thousand Oaks, CA: Sage.

Hill, C. E., Thompson, B. J., and Williams, E. N. (1997). A guide to conducting consensual qualitative research. Couns. Psychol. 25, 517-572. doi: 10.1177/ 0011000097254001

Hoc, J. M. (1991). Effets de l'expertise des opérateurs et de la complexité de la situation dans la conduite d'un processus continu à long délai de réponse: le haut fourneau [Effects of operator expertise and task complexity upon the supervision of a continuous process with long time lags: a blast furnace]. Le Trav. Hum. 54, 225-249.

Hölscher, C., Meilinger, T., Vrachliotis, G., Brösamle, M., and Knauff, M. (2006). Up the down staircase: wayfinding strategies in multi-level buildings. J. Environ. Psychol. 26, 284-299. doi: 10.1016/j.jenvp.2006.09.002

Hughes, J., and Parkes, S. (2003). Trends in the use of verbal protocol analysis in software engineering research. Behav. Inf. Technol. 22, 127-140. doi: 10.1080/ 0144929031000081341

Isenberg, D. J. (1986). Thinking and managing: a verbal protocol analysis of managerial problem solving. Acad. Manag. J. 29, 775-788.

Keller, H., Lamm, B., Abels, M., Yovsi, R., Borke, J., Jensen, H., et al. (2006). Cultural models, socialization goals, and parenting ethnotheories. J. Cross Cult. Psychol. 37, 155-172. doi: 10.1177/0022022105284494

Kesler, T., Tinio, P. P. L., and Nolan, B. T. (2016). What's our position? A critical media literacy study of popular culture websites with eighth-grade special education students. Read. Writ. Q. 32, 1-26. doi: 10.1080/10573569. 2013.857976

Kim, H. S. (2002). We talk, therefore we think? A cultural analysis of the effect of talking on thinking. J. Pers. Soc. Psychol. 83, 828-842. doi: 10.1037/0022-3514. 83.4.828

Lanza, S. T., Collins, L. M., Schafer, J. L., and Flaherty, B. P. (2005). Using data augmentation to obtain standard errors and conduct hypothesis tests in latent class and latent transition analysis. Psychol. Methods 10, 84-100. doi: 10.1037/ 1082-989X.10.1.84

Lay, C., Fairlie, P., Jackson, S., Ricci, T., Eisenberg, J., Sato, T., et al. (1998). Domain-specific allocentrism-idiocentrism. J. Cross Cult. Psychol. 29, 434-460. doi: $10.1177 / 0022022198293004$

Lincoln, Y., and Guba, E. (1999). "Establishing trustworthiness," in Qualitative Research, Vol. III, eds A. Bryman and R. G. Burgess (Thousand Oaks, CA: Sage).

Long, D. L., and Bourg, T. (1996). Thinking aloud: telling a story about a story. Discourse Process. 21, 329-339. doi: 10.1080/0163853960954 4961

Luria, A. R. (1976). Cognitive Development: Its Cultural and Social Foundation, trans. L. Solotaroff. Cambridge, MA: Harvard University Press.

Malek, H. B., Berna, F., and D'Argembeau, A. (2017). Reconstructing the times of past and future personal events. Memory 25, 1402-1411. doi: 10.1080/09658211. 2017.1310251

Meichenbaum, D. (1980). Treating depression. PsycCRITIQUES 25, 879-880. doi: $10.1037 / 019346$

Muñoz, B., Magliano, J. P., Sheridan, R., and McNamara, D. S. (2006). Typing versus thinking aloud when reading: implications for computer-based assessment and training tools. Behav. Res. Methods 38, 211-217. doi: 10.3758/ BF03192771

Muthén, L. K., and Muthén, B. O. (2017). Mplus User's Guide, 8th Edn. Los Angeles, CA: Muthén \& Muthén.
Newell, A., and Simon, H. A. (1972). Human Problem Solving. Englewood Cliffs, NJ: Prentice-Hall.

Nisbett, R. E. (2003). The Geography of Thought: How Asians and Westerners Think Differently and Why. New York, NY: The Free Press.

Parise, A., and Güss, C. D. (2006). TAP: A Thinking-Aloud Analysis Program. Jacksonville, FL: University of North Florida.

Premkumar, G. (1989). A cognitive study of the decision-making process in a business context: implications for design of expert systems. Int. J. Man Mach. Stud. 1, 557-572. doi: 10.1016/0020-7373(89)90016-3

Raitasalo, K., Knibbe, R., and Kraus, L. (2005). Retrieval strategies and cultural differences in answering survey questions on drinking: a crossnational comparison. Addict. Res. Theory 13, 359-372. doi: 10.1080/ 1606635042000334179

Samson, A., Simpson, D., Kamphoff, C., and Langlier, A. (2017). Think aloud: an examination of distance runners' thought processes. Int. J. Sport Exerc. Psychol. 15, 176-189. doi: 10.1080/1612197X.2015.1069877

Santtila, P., Korpela, S., and Häkkänen, H. (2004). Expertise and decision-making in the linking of car crime series. Psychol. Crime Law 10, 97-112. doi: 10.1080/ 1068316021000030559

Scribner, S. (1979). "Modes of thinking and ways of speaking: culture and logic reconsidered," in New Directions in Discourse Processing, ed. R. O. Freedle (Norwood, NJ: Ablex), 223-243.

Scribner, S., and Cole, M. (1981). The Psychology of Literacy. Cambridge, MA: Harvard University Press. doi: 10.4159/harvard.9780674433014

Smagorinsky, P. (2001). Rethinking protocol analysis from a cultural perspective. Annu. Rev. Appl. Linguist. 21, 233-245. doi: 10.1017/S0267190501000149

Strohschneider, S., and Güss, D. (1998). Planning and problem solving: differences between Brazilian and German students. J. Cross Cult. Psychol. 29, 695-716. doi: 10.1177/0022022198296002

Sudman, S., Bradburn, N. M., and Schwartz, N. (eds). (1996). Thinking About Answers: The Application of Cognitive Processes to Survey Methodology. San Francisco, CA: Jossey-Bass.

van de Vijver, F. J. R., and He, J. (2017). "Equivalence in research on positive development of minority children: methodological approaches," in Handbook on Positive Development of Minority Children and Youth, eds N. Cabrera and B. Leyendecker (New York, NY: Springer), 53-66. doi: 10.1007/978-3-31943645-6_4

van de Vijver, F. J. R., and Leung, K. (1997). Methods and Data Analysis for Cross-Cultural Research. Newbury Park, CA: Sage.

van den Bergh, H., and Rijlaarsdam, G. (2001). Changes in cognitive activities during the writing process and relationships with text quality. Educ. Psychol. 21, 373-385. doi: 10.1080/01443410120090777

Van Hooijdonk, C., Maes, A., and Ummelen, N. (2006). "I have been here before": an investigation into spatial verbalizations in hypertext navigation. Inform. Des. J. 14, 8-21. doi: 10.1075/idj.14.1.03hoo

Vreeman, R. C., Nyandiko, W. M., Ayaya, S. O., Walumbe, E. G., and Inui, T. S. (2014). Cognitive interviewing for cross-cultural adaptation of pediatric antiretroviral therapy adherence measurement items. Int. J. Behav. Med. 21, 186-196. doi: 10.1007/s12529-012-9283-9

Wang, Y.-H. (2016). Reading strategy use and comprehension performance of more successful and less successful readers: a think-aloud study. Educ. Sci. 16, 1789-1813. doi: 10.12738/estp.2016.5.0116

Watson, J. B. (1925). Behaviorism. New York, NY: W.W. Norton.

Willis, J. W. (2007). Foundations of Qualitative Research. Thousand Oaks, CA: Sage.

Wilson, T. D. (1994). The proper protocol: validity and completeness of verbal reports. Psychol. Sci. 5, 249-252. doi: 10.1111/j.1467-9280.1994.tb00621.x

Wundt, W. (1888). Selbstbeobachtung und innere Wahrnehmung [Self-observation and inner perception]. Philos. Stud. 1, 615-617.

Conflict of Interest Statement: The author declares that the research was conducted in the absence of any commercial or financial relationships that could be construed as a potential conflict of interest.

Copyright (c) 2018 Güss. This is an open-access article distributed under the terms of the Creative Commons Attribution License (CC BY). The use, distribution or reproduction in other forums is permitted, provided the original author(s) and the copyright owner(s) are credited and that the original publication in this journal is cited, in accordance with accepted academic practice. No use, distribution or reproduction is permitted which does not comply with these terms. 